\title{
ARTICLE Update on the management of alcohol use disorders
}

\author{
Julia M. A. Sinclair (1) \& Aimee 0’Neill (1)
}

\begin{abstract}
Julia Sinclair, MBBS, MRCPsych, MSc, DPhil, is Professor of Addiction Psychiatry at the University of Southampton and an honorary consultant in alcohol liaison with University Hospital Southampton NHS Foundation Trust, UK. She is chair of the Royal College of Psychiatrists' Faculty of Addictions Psychiatry. Her primary research aim is to conduct clinically relevant research into the harms of alcohol use, specifically the impact on clinical outcomes in terms of prevention, engagement and response to treatment. Aimee 0'Neill, MSc $\mathrm{BSocSci}$, is a senior research assistant at the Centre for Workforce Wellbeing - a collaboration between Health Education England (Wessex) and the University of Southampton. With a background in cognitive neuroscience, psychology and organisational psychology, her research interests include stress, burnout and addictions.

Correspondence Professor Julia Sinclair, University Department of Psychiatry, Academic Centre, College Keep, 4-12 Terminus Terrace,

Southampton S014 3DT, UK

Email: julia.sinclair@soton.ac.uk
\end{abstract}

First received 8 Jul 2019 Final revision 9 Sep 2019 Accepted 12 Sep 2019

Copyright and usage (c) The Authors 2019

\section{SUMMARY \\ Alcohol use disorders (AUD) are common, particu- larly in patients attending mental health services. Clinicians are often hesitant to explore with patients their relationship with alcohol and the role that it has in their presenting complaint, despite being ideally placed to optimise on a 'teachable moment' and initiate treatment, where necessary. This article provides an overview of AUD and their identification and management options.}

\section{LEARNING OBJECTIVES}

After reading this article you will be able to:

- understand key concepts and definitions of alcohol use disorders

- recognise and assess alcohol use disorders

- manage alcohol use disorders in clinical settings.

\section{DECLARATION OF INTEREST}

None.

\section{KEYWORDS}

Alcohol use disorders; comorbidity; psychosocial interventions.

Alcohol use disorders (AUD) are common and disabling conditions, with 3 million deaths worldwide (5.3\% of all deaths) and $7.2 \%$ of premature mortality attributable to alcohol consumption in 2016 (World Health Organization 2018). In 2016 approximately $31 \%$ of men and $16 \%$ of women in England reported drinking at increased- or higher-risk levels (Fuller 2017). In 2018 there were 337000 hospital admissions in England (2.1\% of all admissions) primarily attributed to alcohol and 1.1 million (7\%) in which an AUD was the primary or secondary diagnosis (NHS Digital 2018). Alcohol dependence (as per ICD-10; World Health Organization 1992) or severe alcohol use disorder (DSM-5; American Psychiatric Association 2013) is frequently undertreated, with estimates of treatment in less than $10 \%$ of affected of individuals in Europe (Rehm 2013) and 25\% in the USA (Hasin 2007). There is a good evidence base for the effectiveness of treatments for managing alcohol withdrawal symptoms (Amato 2011), assisting relapse prevention and reducing alcohol consumption to help reduce harms (National Institute for Health and Care Excellence [NICE] 2011; Lingford-Hughes 2012; Jonas 2014).

As alcohol is a small molecule that is widely distributed throughout the body, it can cause myriad harms affecting most of the body's organs and systems. As a psychoactive substance, alcohol has a particularly harmful impact on mental health, through intoxication, physical and psychological dependence and withdrawal states, as well as having a detrimental effect on cognitive and affective functioning.

AUD are one of the most prevalent comorbidities in people with mental illness. A Norwegian Patient Registry study found that AUD was the most common comorbid substance use disorder in every diagnostic group (Nesvåg 2015). Five-year prevalence rates of AUD were $4.4 \%$ in people with depression, $4.6 \%$ in those with schizophrenia and $8.1 \%$ in those with bipolar disorder. Similarly, a Danish Psychiatric Register found lifetime prevalence of AUD in individuals with psychoses of $27.6 \%$, in bipolar disorder of $27.9 \%$ and in depression of 20.9\% (Toftdahl 2016). UK studies of psychiatric in-patients have found prevalence rates of comorbid AUD of between 37 and 51\% in men and 13 and $29 \%$ of women on admission (Weaver 2003; Sinclair 2008).

AUD specifically, and other substance use more generally, should be considered the expectation and not the exception for patients attending mental health services, given the population rates of use and the increased likelihood of use in vulnerable groups (Carra 2009). It is well-recognised that people who have a comorbid substance use disorder have worse outcomes than those who do not (e.g. Swartz 2008; Howland 2009; Davis 2010) and yet levels of alcohol use are often poorly documented in patients' notes, and models of care within most mental health services in the UK's National Health Service (NHS) do not encourage integration of treatment for comorbid AUD. This situation is made worse by the commissioning systems within the UK, which have separated provision of care for people with addictions from the NHS and into local authorities, leaving patients frequently inadequately managed in one or other system, or unable to access either. 
The aim of this article is to encourage psychiatrists and all mental health professionals to be more confident and competent in the identification and management of comorbid AUD to enhance clinical practice and improve outcomes for patients.

\section{Definitions}

Until recently both ICD and DSM dichotomised the disorders associated with alcohol use into 'dependence' for the most severe use (ICD-10; World Health Organization 1992; DSM-IV; American Psychiatric Association 2000) and 'harmful use' (ICD-10) or 'alcohol abuse' (DSM-IV) for patients with less severe complications from their alcohol use. DSM-5 (American Psychiatric Association 2013) marks a change in how alcohol use disorders are conceptualised, with a single broader diagnosis of 'alcohol use disorder'. This defines the impact of alcohol use on an individual as a spectrum from mild through moderate to severe, better reflecting the natural history of the disorder, removing some of the stigma and encouraging a broader perspective to be taken in management than the earlier diagnostic systems engender.

DSM-5 lists 11 potential criteria for alcohol use disorder, covering four main aspects of alcohol use (impaired control, social impairment, risky use and pharmacological effects). Meeting the criteria for any 2-3 of these is defined as mild alcohol use disorder, $4-5$ as moderate and 6 or more as severe (Box 1).

ICD-10 continues to keep the dichotomised definitions of 'harmful use' (F10.1) and 'dependence syndrome' (F10.2) in relation to psychoactive substances, but this is likely to change in ICD-11.

ICD-10 'harmful use' is defined as a pattern of use that is causing damage to health. The damage may be physical (e.g. alcohol-related liver disease) or mental (e.g. episodes of depressive disorder). A 'dependence syndrome' is diagnosed when a person has three or more physiological, behavioural and cognitive phenomena clustering together over the course of a year, in which the substance (e.g. alcohol) use takes on a much higher priority than other previously valued behaviours. A criterion common across the diagnostic classifications for dependence (or 'severe alcohol use disorder' in DSM-5) is the appearance of a withdrawal syndrome in the relative, or absolute, absence of alcohol. The symptoms and potential complications are covered in detail in the section 'Management of alcohol withdrawal' below.

Interestingly, neither diagnostic system includes the actual level of alcohol consumed (in terms of units per day) as part of its criteria, and there is a further argument that being able simply to note how much an individual is drinking may be a more objective and less stigmatising way of recording current alcohol use (Nutt 2014). Although this has good face validity, in terms of recognising the range of harms that alcohol might cause across the spectrum of use, it does not include any measure of impairment (physical, psychological or social), which is not always correlated with level of use, especially in people with mental health problems, who may develop significant impairment from alcohol at lower levels of consumption.

The most recent guidance from the UK Chief Medical Officers (Department of Health 2016a) has redefined the levels of lower-risk drinking to take into account the accruing evidence of harm on long-term conditions (including cancer) at lower sustained levels of alcohol consumption. Lower-risk drinking is now defined as 'a level around and a little below that which would be suggested by an analysis of absolute 1\% lifetime risk of death' (Department of Health 2016b: p.15) and, based on

BOX 1 DSM-5 criteria for alcohol use disorder

In the past year have you:

1 Had times when you ended up drinking more, or for longer, than you intended?

2 More than once wanted to cut down or stop drinking, or tried to, but couldn't?

3 Spent a great deal of time on activities necessary to obtain alcohol, use alcohol or recover from its effects?

4 Spent a lot of time drinking? Or being sick or getting over other after-effects?

5 Found that drinking - or being sick from drinking - often interfered with taking care of your home or family? Or caused job troubles? Or school problems?

6 Continued to drink even though it was causing trouble with your family or friends?

7 Given up or cut back on activities that were important or interesting to you, or gave you pleasure, in order to drink?

8 More than once got into situations while or after drinking that increased your chances of getting hurt (such as driving, swimming, using machinery, walking in a dangerous area or having unsafe sex)?
9 Continued to drink even though it was making you feel depressed or anxious or adding to another health problem? Or after having had a memory blackout?

10 Had to drink much more than you once did to get the effect you want? Or found that your usual number of drinks had much less effect than before?

11 Found that when the effects of alcohol were wearing off, you had withdrawal symptoms? (American Psychiatric Association 2013) 
BOX 2 UK Chief Medical Officers' guidelines on drinking

The CMO guidelines have three main recommendation areas:

A weekly guideline for regular drinkers

- Try not to drink more than 14 units per week to avoid the health risks associated with low-level drinking

- If you regularly drink 14 units per week, spread it out over 3 or more days

- Any amount of regular drinking increases the likelihood of a multitude of illnesses (e.g. mouth/throat/breast cancer)

- Cut down regular drinking and implement several drink-free days during the week

Guidance on single drinking episodes

- Limit the amount you drink on any single occasion
- Drink slowly, alternate with water, and eat food

- Plan ahead (e.g. how to get home safely)

- Be aware that alcohol affects some groups of people more than others (e.g. those susceptible to falls or people on certain medications)

Pregnancy and drinking guideline

- To keep risks to the baby at a minimum, do not drink any alcohol

- Drinking during pregnancy can cause longterm harm to the baby and the more you drink, the greater the risk

- If you have drunk small amounts of alcohol before finding out you are pregnant, or during pregnancy, risk of harm to the baby is likely to be low

(Department of Health 2016a) the integration of harms across a range of conditions, this has been set at 14 (UK) units of alcohol per week for both men and women. Box 2 outlines the $\mathrm{CMO}$ recommendations in three main areas: regular drinking, single occasions of drinking and drinking in pregnancy.

\section{Alcohol-related health literacy among clinicians}

Health professionals often feel uncomfortable asking about alcohol use, especially if they do not feel confident in their ability to estimate levels of alcohol consumption. Studies of medical students have shown that overall levels of alcohol health literacy (e.g. being able to estimate units of alcohol or understand the content of common alcohol-containing drinks) are low (Sinclair 2016a, 2019a).

There appears to be a positive correlation between clinicians' personal alcohol consumption (Das 2009, 2014) and being more prepared to ask about, and manage, patients' alcohol problems. The same was found in those who engaged in more CPD about alcohol (Kaner 2001).

In a recent study of women presenting to breast health services concerned about breast cancer, we found that there was often what we termed a 'collusion of denial'. This was where staff stated that they assumed that if patients were concerned or wished to talk about alcohol they would raise the topic, whereas patients assumed that if alcohol was a relevant factor in the management of their health then staff (surely) would be asking about it (Sinclair 2019b).
All clinicians need to have the competencies to feel confident to identify, assess and manage AUD (NICE 2011; Sinclair 2012). The Wessex Recent In-Patient Suicide Study (King 2001) found that there were very low levels of recorded alcohol histories in patient notes, but that where alcohol use was identified it appeared protective against suicide. In a recent audit, a similar level of poor recording was found for patients with sufficiently severe AUD to require alcohol withdrawal management on admission (Paton 2015).

\section{Alcohol units and $A B V$ percentages}

Knowing how many units of alcohol a person drinks per day or week will give an objective and useful baseline level of alcohol use. This requires health professionals to be aware of how to estimate alcohol use and take the responsibility for asking patients, who frequently expect to be asked, about their alcohol use. One unit of alcohol in the UK is equivalent to $8 \mathrm{~g}$ or $10 \mathrm{~mL}$ of pure alcohol. Labelling of alcohol requires the alcohol by volume $(\mathrm{ABV})$ percentage to be listed on products, which enables an easy estimation of alcohol content. The $\mathrm{ABV}$ is equivalent to the number of units in $1 \mathrm{~L}$ of that drink. Therefore, if a particular drink (e.g. spirits) is $40 \% \mathrm{ABV}$ there will be 40 units in $1 \mathrm{~L}$, 4 in $100 \mathrm{~mL}$ and a single unit in a $25 \mathrm{~mL}$ 'shot'. Even with limited personal knowledge of alcoholcontaining beverages, a clinician should be able to gain a good approximate alcohol history by asking about the approximate strength and volume of alcohol consumed. This is a basic competence needed to identify patients who may have an AUD so that an effective management plan can be tailored to their needs.

\section{Identification of AUD}

\section{Validated tools to assist identification}

Use of a validated screening tool such as the Alcohol Use Disorders Identification Test - Consumption (AUDIT-C; Bush 1998), which comprises the first three questions of the AUDIT (Saunders 1993), is recommended as a routine part of all clinical assessments, and also requires an understanding of alcohol units (discussed above) to guide a patient through answering it effectively. The AUDIT-C gives information on level of consumption, generating a score between 0 and 12 and indicating when a more comprehensive assessment is required (a score $\geq 5$ ). If a more comprehensive assessment is indicated, the full 10 questions of the AUDIT are advised (with a maximum score of 40), which include sections on harms and symptoms of dependence (Table 1). A score of 0-7 indicates low risk, 8-15 increasing risk, $\geq 16$ higher risk, with $\geq 20$ 
TABLE 1 Alcohol Use Disorders Identification Test (AUDIT) and AUDIT-C ${ }^{a}$ questions

\begin{tabular}{|c|c|c|c|c|c|c|}
\hline \multirow[b]{2}{*}{ Questions } & \multicolumn{5}{|c|}{ Scoring system } & \multirow{2}{*}{$\begin{array}{l}\text { Your } \\
\text { score }\end{array}$} \\
\hline & 0 & 1 & 2 & 3 & 4 & \\
\hline 1. How often do you have a drink containing alcohol? ${ }^{a}$ & Never & Monthly or less & 2-4 times per month & $\begin{array}{l}\text { 2-3 times per } \\
\text { week }\end{array}$ & 4 times or more per week & \\
\hline $\begin{array}{l}\text { 2. How many units of alcohol do you drink on a typical day } \\
\text { when you are drinking? }\end{array}$ & $0-2$ & $3-4$ & $5-6$ & $7-9$ & 10 or more & \\
\hline $\begin{array}{l}\text { 3. How often have you had } 6 \text { or more units (if female) or } 8 \text { or } \\
\text { more (if male) on a single occasion in the last year? }\end{array}$ & Never & Less than monthly & Monthly & Weekly & Daily or almost daily & \\
\hline \multicolumn{7}{|l|}{ Total AUDIT-C score (max. 12) } \\
\hline $\begin{array}{l}\text { 4. How often during the last year have you found that you } \\
\text { were not able to stop drinking once you had started? }\end{array}$ & Never & Less than monthly & Monthly & Weekly & Daily or almost daily & \\
\hline $\begin{array}{l}\text { 5. How often during the last year have you failed to do what } \\
\text { was normally expected from you because of your } \\
\text { drinking? }\end{array}$ & Never & Less than monthly & Monthly & Weekly & Daily or almost daily & \\
\hline $\begin{array}{l}\text { 6. How often during the last year have you needed an } \\
\text { alcoholic drink in the morning to get yourself going after } \\
\text { a heavy drinking session? }\end{array}$ & Never & Less than monthly & Monthly & Weekly & Daily or almost daily & \\
\hline $\begin{array}{l}\text { 7. How often during the last year have you had a feeling of } \\
\text { guilt or remorse after drinking? }\end{array}$ & Never & Less than monthly & Monthly & Weekly & Daily or almost daily & \\
\hline $\begin{array}{l}\text { 8. How often during the last year have you been unable to } \\
\text { remember what happened the night before because you } \\
\text { had been drinking? }\end{array}$ & Never & Less than monthly & Monthly & Weekly & Daily or almost daily & \\
\hline $\begin{array}{l}\text { 9. Have you or somebody else been injured as a result of } \\
\text { your drinking? }\end{array}$ & No & & Yes, but not in the past year & & Yes during the past year & \\
\hline $\begin{array}{l}\text { 10. Has a relative or friend, doctor or other health worker } \\
\text { been concerned about your drinking or suggested that } \\
\text { you cut down? }\end{array}$ & No & & Yes, but not in the past year & & Yes during the past year & \\
\hline Total AUDIT score (max. 40) & & & & & & \\
\hline
\end{tabular}

a. Questions 1-3 comprise the Alcohol Use Disorders Identification Test - Consumption (AUDIT-C)

Source: Babor TF, Higgins-Biddle JC, Saunders JB, et al. (2001) AUDIT: The Alcohol Use Disorders Identification Test. Guidelines for Use in Primary Health Care (2nd edn). World Health Organization (https:// apps.who.int/iris/handle/10665/67205)

indicating possible dependence. The CAGE screening questions (Do you think you should Cut down? Do you get Annoyed being asked about your alcohol? Do you feel Guilty about the amount you drink? Do you need an 'Eye opener'?) are not recommended, as CAGE gives no objective assessment of the frequency and quantity of alcohol use, and it has low sensitivity for identifying moderate levels of harm (which may still be a significant contributor to the patient's mental state) (Shields 2004). In addition, it is counter to the principles of motivational interviewing and may be countertherapeutic (NICE 2011).

\section{Management principles}

The trajectory of alcohol use from occasional, through habitual to daily dependent use is a complex interplay between genetic vulnerabilities, environmental factors, and habitual and learned behaviours. Management of patients presenting with AUD will need to be tailored depending on: the presenting complaint; level and duration of use; severity of dependence; the presence of any additional comorbid substance use disorders; physical and/or mental health conditions; and motivation to change.

Management always needs to start with engagement of the patient in the process and understanding their initial goals for treatment (which may well change with time). Following this, the focus of treatment may be on reduction of use, medically assisted withdrawal (detoxification or 'detox') or relapse prevention. A psychological framework is the basis of all AUD treatment, exclusively so at less severe levels, but all pharmacological management of more severe AUD needs to be delivered within such a framework. In addition, patients may benefit from adjuvant psychological therapies (e.g. mindfulness (Chiesa 2014), cognitive-behavioural therapy (McHugh 2010)) to help manage comorbid psychological distress and develop broader psychological resilience and alternative coping strategies to alcohol use.

\section{Engagement, brief interventions and psychosocial principles}

Psychosocial interventions underpin all management of AUD, exclusively so at increased-risk drinking levels (non-dependent use $>14$ units of alcohol per week), but also for patients with alcohol dependence who require pharmacological interventions as well. There is a substantial evidence base for the effectiveness of brief interventions, which can be as simple as giving someone an information leaflet 
(Kaner 2018), but making the 'teachable moment' more salient, by linking the information to the patient's own concerns and giving clear and consistent advice embedded within the wider management plan, may enhance their effectiveness.

For some, simply being made aware of the amount they are drinking (by giving feedback on their answers to the AUDIT-C) may be sufficient to make changes. For others, this is a necessary beginning but not in itself sufficient to alter their alcohol consumption. Motivational interviewing principles are a key part of all psychosocial interventions aiming to engage people's intrinsic motivation to change their behaviour (Rollnick 1995). It is used more broadly in many aspects of practice and is increasingly a core psychiatric competence. It is used in a range of techniques, including understanding the patient's frame of reference and degree of readiness to change and affirming patient's agency and choices. An excellent summary of principles and practice is provided in an earlier article in this journal (Treasure 2004).

In addition, one of the simplest behaviour change techniques with the best evidence for effectiveness is monitoring of alcohol consumption (Michie 2012). This not only gives a prospective, ideally daily, record of what is being drunk, but more importantly makes consumption more conscious, helps the patient identify their patterns of behaviour and affords the opportunity for discussion about how they may be able to make changes. There are many resources to enable people to do this, and the Public Health England resources on the One You website (https://www.nhs.uk/oneyou/for-yourbody/drink-less/) are a good place to signpost both patients and carers, as well as colleagues looking for an introduction to brief alcohol interventions. For many people, especially those with comorbid mental illness, alcohol use has become a significant social activity, and so any serious attempts to enable change will need to consider how else they might spend their time and engage in other activities that are exclusive of alcohol consumption.

The NICE guidelines (NICE 2011) recommend that, for higher-risk drinkers and people with mild alcohol dependence, psychological interventions (such as cognitive-behavioural therapies, behavioural therapies or social network and environmentbased therapies) focused specifically on alcoholrelated cognitions, behaviour, problems and social networks should be offered. For higher-risk drinkers who have a regular partner who is willing to participate in treatment, behavioural couple's therapy may be of benefit.

For many patients who present in crisis, their physical symptoms of alcohol withdrawal are the most pressing medical management problem needing to be addressed. However, medically assisted withdrawal is an opportunity for engagement and fuller assessment and should never be undertaken in isolation, but always as the first step in a wider harm reduction or relapse prevention plan.

\section{Management of alcohol withdrawal}

Identification of alcohol dependence and need for medically assisted withdrawal

Although many patients can be successfully withdrawn from alcohol in community settings (Nadkarni 2017), withdrawal is best undertaken as part of a planned treatment package based on local protocols with good monitoring and support, to minimise risks and optimise treatment outcomes. Unplanned medically assisted withdrawal for patients presenting in crisis is not advised in the community (NICE 2011).

For those with mild to moderate dependence, and no significant other comorbidities, a planned outpatient-based medically assisted withdrawal programme in the community consisting of medication and psychosocial support (including motivational interviewing), is recommended. This should be followed by an intensive community programme that includes relapse prevention medication (see 'Management of relapse prevention' section below), psychological interventions such as individual treatments, group treatments, psychoeducational interventions, help to attend self-help groups, family and carer support and involvement, and case management (NICE 2011).

For patients admitted to psychiatric in-patient units, who may require an unplanned medically assisted withdrawal from alcohol as part of their treatment, NICE quality standards apply (NICE 2011). Using these quality standards, an audit by the Prescribing Observatory for Mental Health (POMH-UK) examined the clinical practice standards of 43 mental health trusts using the cases of 1143 patients who required a medically assisted withdrawal from alcohol while on an in-patient ward (Paton 2015). Of those in the audit, 70\% were undergoing unplanned withdrawal and $21 \%$ were undergoing their first recorded detoxification. Of note, only one third recorded the number of years since the alcohol problem was first identified, and just over two-thirds recorded the daily number of units consumed prior to admission. No standardised assessments of alcohol use or withdrawal were used in half of the cases audited, suggesting inadequate assessment to formulate an appropriate management plan for the majority of patients.

Patients identified as being at risk of alcohol withdrawal syndrome need to be monitored regularly, ideally using a standardised tool - such as the 
TABLE 2 Timing, symptoms and prognosis of alcohol withdrawal syndrome (AWS) and delirium tremens

\begin{tabular}{|ccc|}
\hline & Alcohol withdrawal syndrome & Delirium tremens \\
\hline $\begin{array}{c}\text { Timing } \\
\text { Onset } \\
\text { Duration }\end{array}$ & $1-2$ days & $2-5$ days \\
Symptoms & $1-3$ days & $3-12$ days \\
Somatic & Tremor, nausea, sleep disturbance, increased & \\
heart rate, hypertension (seizures) & Severe AWS symptoms + altered \\
Psychotic & Fear, low mood, agitation & Marked over-arousal \\
Prognosis & Illusions, fleeting hallucinations & Hallucinations, delusions \\
\hline
\end{tabular}

Clinical Institute Withdrawal Assessment for Alcohol, Revised (CIWA-Ar; Sullivan 1989) or the Glasgow Modified Alcohol Withdrawal Scale (GMAWS; Benson 2012) - to evaluate the need to start medication. This is particularly important in patients with a history of complicated or severe alcohol withdrawal, and those who have a history of seizures during alcohol withdrawal.

There have been numerous reviews of the evidence for medically assisted withdrawal from alcohol (Minozzi 2010; NICE 2010, 2011; Amato 2011) and, taken together with expert opinion (Lingford-Hughes 2012), the clear consensus for management of withdrawal on general in-patient wards is to start a withdrawal regime with a fixed dose of a benzodiazepine (most commonly chlordiazepoxide) for 5-7 days. Given the significant interpersonal variation in alcohol withdrawal symptoms (Table 2), the response requires careful monitoring to ensure that patients are adequately treated but not oversedated. The length of time before patients demonstrate signs of alcohol withdrawal is also variable. Some will start exhibiting quite severe alcohol withdrawal symptoms despite still having significant amounts of alcohol in their system; this should not be a reason to withhold medication but seen as an indicator of the likely severity of withdrawal. For others, withdrawal symptoms will not start to present until after they have been in hospital and off alcohol for $24-48 \mathrm{~h}$ : this can be especially problematic in terms of correct diagnosis and management if patients are missed as being at risk of alcohol withdrawal syndrome at admission.

All patients screened as likely to be alcohol dependent (scoring $\geq 20$ on the AUDIT) or diagnosed as such should also be assessed for WernickeKorsakoff syndrome and the need for thiamine and other vitamin B supplementation (discussed in the section 'Wernicke-Korsakoff syndrome' below).

\section{Management of complicated alcohol withdrawal}

The majority of patients correctly identified in the early stages of alcohol withdrawal syndrome and managed on a reducing regime of chlordiazepoxide (most NHS trusts have their own policy for how this should be done) have an uncomplicated course. However, for a minority of patients, their outcomes are complicated by the development of delirium tremens or Wernicke-Korsakoff syndrome, and those at high risk will require admission to an acute medical setting, as the facilities required to manage them (intravenous access, etc.) are rarely available in psychiatric settings.

\section{Delirium tremens}

Delirium tremens is more likely to present in older, medically compromised patients with a long history of alcohol dependence and poor nutritional state. It is often preceded by symptoms of alcohol withdrawal, and seizures may herald its onset. It has a fluctuating course, and in addition to the symptoms of alcohol withdrawal syndrome, patients have a range of clinical features, including autonomic hyperactivity, marked agitation, clouding of consciousness, perceptual disturbances and paranoid delusions. These may be misdiagnosed as a psychotic episode, but the time frame involved and associated autonomic arousal (Table 2) should help with correct diagnosis. All patients should be transferred to an acute medical ward for management, as left untreated the mortality rate is $1-15 \%$. Delirium tremens usually lasts 2-3 days but can last for several weeks. The first-line medication for both prevention and treatment are benzodiazepines, with the aim of achieving a light sedation. Antipsychotic medications should only be used as an adjuvant to adequate diazepam doses to control more intractable agitation (Haber 2009).

\section{Wernicke-Korsakoff syndrome}

Wernicke-Korsakoff syndrome should be assumed in any confused alcohol-dependent patient until proven otherwise. Although the classic triad of symptoms for the syndrome are confusion, ataxia and ophthalmoplegia, in reality confusion may be the only sign present in $80 \%$ of patients. Owing to 
TABLE 3 Relapse prevention medications

\begin{tabular}{|c|c|c|c|c|}
\hline Drug & Standard dose ${ }^{a}$ & Cautions & Common side-effects & Notes related to comorbid psychiatric conditions \\
\hline Acamprosate & $\begin{array}{r}2 \times 333 \mathrm{mg} \text { three } \\
\text { times a day }\end{array}$ & $\begin{array}{r}\text { Cirrhosis; elderly; } \\
\text { underweight }\end{array}$ & $\begin{array}{l}\text { Diarrhoea (usually settles } \\
\text { within } 7 \text { days) }\end{array}$ & No concerns about prescribing; limited interactions \\
\hline Naltrexone & 50 mg daily & $\begin{array}{l}\text { Cirrhosis; patient on } \\
\text { opioids }\end{array}$ & Nausea & $\begin{array}{l}\text { Recommended as first line for relapse prevention in bipolar disorder } \\
\text { (Goodwin 2016); no concerns about prescribing; opioid antagonist - so } \\
\text { check concurrent use of opioids }\end{array}$ \\
\hline Disulfiram & 200-250 mg daily & $\begin{array}{l}\text { Suicidal patient; high } \\
\text { cardiovascular risk }\end{array}$ & $\begin{array}{l}\text { Metallic taste; interactions } \\
\text { with alcohol }\end{array}$ & $\begin{array}{l}\text { Ideal to have medication 'witnessed'; patient must be engaged to avoid } \\
\text { alcohol in all forms; no recent evidence for precipitating psychosis at } \\
\text { modern doses }\end{array}$ \\
\hline Nalmefene & $\begin{array}{l}18 \mathrm{mg} \text { daily } \\
\text { if required }\end{array}$ & Patient on opioids & $\begin{array}{l}\text { Gastric side-effects; perceptual } \\
\text { disturbance less common but } \\
\text { may be severe }\end{array}$ & $\begin{array}{l}\text { No evidence, but likely as for naltrexone; licensed to assist reduction in } \\
\text { patients not in need of immediate detoxification; opioid antagonist - } \\
\text { so check concurrent use of opioids }\end{array}$ \\
\hline Baclofen $^{\text {b }}$ & 30-90 mg daily & $\begin{array}{l}\text { Mood disorders; risk of } \\
\text { overdose; renal } \\
\text { disease }\end{array}$ & Sedation particular risk in overdose & $\begin{array}{l}\text { May precipitate mania; risk of respiratory depression in overdose; caution } \\
\text { with impulsive disorders }\end{array}$ \\
\hline
\end{tabular}

a. Check the $B N F$ (https://bnf.nice.org.uk/) for full details.

b. Off-label prescribing

the poor absorption of thiamine in the gut of patients with alcohol dependence, and the high levels needed in the cerebrospinal fluid to correct the deficiency, parenteral vitamins B and C (Pabrinex ${ }^{\circ}$ ) ideally should be given. Where this is not possible, and Wernicke-Korsakoff syndrome is only suspected rather than diagnosed, intramuscular thiamine may be used. However, this can be unpleasant and painful for the patient, so transfer to an acute medical ward for assertive management of the syndrome (two pairs of ampoules of Pabrinex ${ }^{\circledast}$ intravenously three times a day for 5-7 days, or until no further improvement in cognition is seen; Thomson 2013) should be considered.

\section{Managed reduction of alcohol use in mild dependence}

For patients drinking at mild to moderate dependent levels but not in need of immediate withdrawal from alcohol, the opioid antagonist nalmefene may reduce alcohol consumption by reducing the positive reinforcing, and pleasurable, effects of alcohol as well as enhancing its sedative and dysphoric properties. Nalmefene is an opioid system modulator, acting as a mu receptor antagonist and kappa receptor partial agonist, but has no opioid mu agonist activity or abuse potential. It is licensed in the UK and Europe for the reduction of alcohol consumption in people not requiring medically assisted withdrawal and can be taken on an 'as required' basis, up to once a day $(20 \mathrm{mg})$. It does not need to be started within specialist services and, as with the other medications, should be given alongside psychosocial support (NICE 2014).

\section{Management of relapse prevention}

As part of the medically assisted withdrawal, a plan for relapse prevention management, including the initiation of relapse prevention medication and referral to specialist care for continuing management and support, needs to be discussed (NICE 2011; Lingford-Hughes 2012). However, the POMHUK audit (Paton 2015) found that, for patients admitted under general psychiatric care, 85\% were not started on any relapse prevention medication (86\% at re-audit) and only 39\% were under the care of an NHS specialist alcohol service, falling to $31 \%$ at re-audit. Ongoing management for AUD was provided by the mental health team in $26 \%$ of cases (29\% at re-audit), with only $5 \%$ managed by a dual diagnosis worker or service. In both audits, no clear plans to address alcohol use had been drawn up for almost $20 \%$ of patients. This reflects a broader problem in the management of AUD, where patients (and clinicians) often mistakenly believe that 'detox' is the treatment, rather than the gateway to ongoing management.

NICE (2011) recommends that acamprosate or naltrexone be offered as the first-line treatment for relapse prevention for patients with moderate to severe alcohol dependence. Broadly, acamprosate has the better evidence for helping patients to maintain abstinence $(\mathrm{RR}=0.83,95 \%$ CI $0.77-0.88$; NICE 2011), whereas naltrexone may be more effective in patients who have the occasional lapse, to prevent the return to heavy drinking $(\mathrm{RR}=$ 0.83, 95\% CI 0.75-0.91; NICE 2011). On the basis of this evidence, it has been recommend that naltrexone is the first-line choice for patients with bipolar disorder (Goodwin 2016). There is a limited evidence base for the use of either acamprosate or naltrexone in patients with a range of comorbid psychiatric conditions, however, based on the evidence that is available, and an understanding of the basic psychopharmacology of the two drugs, 
there are no specific contraindications for their use in patients with comorbid psychiatric conditions (Sinclair 2016b).

Disulfiram previously was contraindicated in patients at risk of psychosis, but this was when doses were considerably higher (2-3 g/day compared with 200-250 mg), and this risk is now not significant (Lingford-Hughes 2012). However, given the safety concerns when taken with alcohol, disulfiram is most appropriate in patients who are keen to take it to help manage dips in motivation and who are supported by family or carers prepared to 'witness' the medicine being taken daily. In addition, all patients will require risk assessment and ongoing monitoring for possible suicidal behaviour and they need to be aware of the variable response when taking disulfiram with alcohol (including mouthwashes and hand gels), so it might only be suitable for a relatively small proportion of people.

Baclofen (a $\mathrm{GABA}_{\mathrm{B}}$ receptor agonist) is not licensed for use in alcohol dependence (except in France) but there is now a growing evidence base for this use, although the studies show variable results (De Beaurepaire 2018). It is not metabolised by the liver and is therefore likely to be of particular use in patients with alcohol-related liver disease, in whom licensed relapse prevention medications are contraindicated. A recent international consensus (Agabio 2018) advised particular caution in patients with mood disorders, as it can increase the risk of hypomanic and manic episodes, and in patients with suicidal ideation or a history of suicide attempts, because of depression of the central nervous system following overdose or in combination with other sedative drugs. Table 3 provides prescribing information for relapse prevention medications.

All people seeking help for alcohol use disorders should be given information on the value and availability of community support networks and self-help groups (e.g. Alcoholic Anonymous, SMART Recovery, Soberistas). Details for all of these are easily accessible online, but active facilitation in attending meetings or accessing online support is recommended (NICE 2011).

\section{Conclusions}

Alcohol use disorders are common, disabling conditions that frequently complicate the presentation and treatment of a range of comorbid psychiatric conditions. Systematic screening of all patients presenting to mental health services will help identify those who are drinking at increased-risk levels and enable appropriate interventions to be integrated into a holistic management plan. For many clinicians, learning to accurately assess levels of alcohol consumption and working to improve their confidence in talking with patients about their alcohol use would help increase their competence in managing patients with AUD. An open clinical discussion is likely to reduce the stigma that patients feel about their problematic alcohol use and help improve outcomes. Structured tools such as the AUDIT are helpful in identifying the level of risk from alcohol and guide the need for a further comprehensive assessment. All patients identified as having alcohol dependence and being at risk of alcohol withdrawal syndrome require a thorough assessment of their alcohol use to evaluate the need for medically assisted alcohol withdrawal and relapse prevention medication.

\section{References}

Agabio R, Sinclair JM, Addolorato G, et al (2018) Baclofen for the treatment of alcohol use disorder: the Cagliari Statement. Lancet Psychiatry, $\mathbf{5}$ : 957-60.

Amato L, Minozzi S, Davoli M (2011) Efficacy and safety of pharmacological interventions for the treatment of the Alcohol Withdrawal Syndrome. Cochrane Database of Systematic Reviews, 6: CD008537.

American Psychiatric Association (2000) Diagnostic and Statistical Manual of Mental Disorders (4th edn text revision) (DSM-IV-TR). APA.

American Psychiatric Association (2013) Diagnostic and Statistical Manual of Mental Disorders (5th edn) (DSM-5). American Psychiatric Publishing

Benson G, McPherson A, Reid S (2012) An alcohol withdrawal tool for use in hospitals. Nursing Times, 108: 15-7.

Bush K, Kivlahan DR, McDonell MB, et al (1998) The AUDIT alcohol consumption questions (AUDIT-C): an effective brief screening test for problem drinking. Archives of Internal Medicine, 158: 1789-95.

Carra G, Johnson S (2009) Variations in rates of comorbid substance use in psychosis between mental health settings and geographical areas in the UK. Social Psychiatry and Psychiatric Epidemiology, 44: 429-47.

Chiesa A, Serretti A (2014) Are mindfulness-based interventions effective for substance use disorders? A systematic review of the evidence. Substance Use \& Misuse, 49: 492-512.

Das AK, Corrado OJ, Kyerematen E, et al (2009) Do doctors understand alcohol units? Clinical Medicine, 9: 525-7.

Das AK, Corrado OJ, Sawicka Z, et al (2014) Junior doctors' understanding of alcohol units remains poor. Clinical Medicine, 14: 141-4.

Davis LL, Wisniewski SR, Howland RH, et al (2010) Does comorbid substance use disorder impair recovery from major depression with SSRI treatment? An analysis of the STAR*D level one treatment outcomes. Drug and Alcohol Dependence, 107: 161-70.

De Beaurepaire R, Sinclair JM, Heydtmann M, et al (2018) The use of baclofen as a treatment for alcohol use disorder: a clinical practice perspective. Frontiers in Psychiatry, 9: 708.

Department of Health (2016a) UK Chief Medical Officers' Low Risk Drinking Guidelines. Department of Health.

Department of Health (2016b) Alcohol Guidelines Review - Report from the Guidelines Development Group to the UK Chief Medical Officers. Department of Health.

Fuller E, Mindell J, Prior G (2017) Summary. In Health Survey for England 2016. NHS Digital (https://digital.nhs.uk/data-and-information/publications/ statistical/health-survey-for-england/health-survey-for-england-2016). Accessed 1 July 2019.

Goodwin G, Haddad P, Ferrier I, et al (2016) Evidence-based guidelines for treating bipolar disorder: revised third edition recommendations from the British Association for Psychopharmacology. Journal of Psychopharmacology, 30: 495-53.
MCO answers

$1 d \quad 2$ a 3 e 4 c 5 b 
Haber P, Lintzeris N, Proude E, et al (2009) Guidelines for the Treatment of Alcohol Problems. University of Sydney.

Hasin DS, Stinson FS, Ogburn E, et al (2007) Prevalence, correlates, disability, and comorbidity of DSM-IV alcohol abuse and dependence in the United States: results from the National Epidemiologic Survey on Alcohol and Related Conditions. Archives of General Psychiatry, 64 830-42.

Howland RH, Rush AJ, Wisniewski SR, et al (2009) Concurrent anxiety and substance use disorders among outpatients with major depression: clinical features and effect on treatment outcome. Drug and Alcohol Dependence, 99: 248-60.

Jonas DE, Amick HR, Feltner C, et al (2014) Pharmacotherapy for adults with alcohol use disorders in outpatient settings: a systematic review and meta-analysis. JAMA, 311: 1889-900.

Kaner EF, Wutzke S, Saunders JB, et al (2001) Impact of alcohol education and training on general practitioners' diagnostic and management skills: findings from a World Health Organization collaborative study. Journal of Studies on Alcohol, 62: 621-7.

Kaner EF, Beyer FR, Muirhead C, et al (2018) Effectiveness of brief alcoho interventions in primary care populations. Cochrane Database of Systematic Reviews, 2: CD004148.

King EA, Baldwin DS, Sinclair JM, et al (2001) The Wessex Recent InPatient Suicide Study, 1: case-control study of 234 recently discharged psychiatric patient suicides. British Journal of Psychiatry, 178: 531-6.

Lingford-Hughes AR, Welch S, Peters L, et al (2012) BAP updated guidelines: evidence-based guidelines for the pharmacological management of substance abuse, harmful use, addiction and comorbidity: recommendations from BAP. Journal of Psychopharmacology, 26: 899-952.

McHugh RK, Hearon BA, Otto MW (2010) Cognitive behavioral therapy for substance use disorders. Psychiatric Clinics, 33: 511-25.

Michie S, Whittington C, Hamoudi Z, et al (2012) Identification of behaviour change techniques to reduce excessive alcohol consumption. Addiction, 107: 1431-40.

Minozzi S, Amato L, Vecchi S, et al (2010) Anticonvulsants for alcohol withdrawal. Cochrane Database of Systematic Reviews, 3: CD005064.

Nadkarni A, Endsley P, Bhatia U, et al (2017) Community detoxification for alcohol dependence: a systematic review. Drug and Alcohol Review, 36: 389-99.

Nesvåg R, Knudsen GP, Bakken IJ, et al (2015) Substance use disorders in schizophrenia, bipolar disorder, and depressive illness: a registry-based study. Social Psychiatry and Psychiatric Epidemiology, 50: 1267-76.

NHS Digital (2018) Statistics on Alcohol: England, 2018. Health and Social Care Information Centre (https://files.digital.nhs.uk/AD/C3036E/alc-eng2018-rep.pdf).

National Institute for Health and Care Excellence (2010) Alcohol Use Disorders: Diagnosis and Clinical Management of Alcohol-Related Physical Complications (Clinical Guideline CG100). NICE.

National Institute for Health and Care Excellence (2011) Alcohol-Use Disorders: Diagnosis, Assessment and Management of Harmfu Drinking (High-Risk Drinking) and Alcohol Dependence (Clinical Guideline CG115). NICE.

National Institute for Health and Care Excellence (2014) Nalmefene for Reducing Alcohol Consumption in People with Alcohol Dependence (Technology Appraisal Guidance TA325). NICE.

Nutt DJ, Rehm J (2014) Doing it by numbers: a simple approach to reducing the harms of alcohol. Journal of Psychopharmacology, 28: 3-7.

Paton C, Chee S, Drummond C, et al (2015) Medically assisted withdrawal from alcohol: an audit of practice in acute adult psychiatric wards in the
UK conducted by the Prescribing Observatory for Mental Health (POMHUK). Journal of Psychopharmacology, 29(issue 8 suppl): A109.

Rehm J, Shield K, Gmel G, et al (2013) Modeling the impact of alcohol dependence on mortality burden and the effect of available treatment interventions in the European Union. European Neuropsychopharmacology, 23: 89-97.

Rollnick S, Miller WR (1995) What is motivational interviewing? Behavioural and Cognitive Psychotherapy, 23: 325-34.

Saunders JB, Aasland OG, Babor TF, et al (1993) Development of the Alcohol Use Disorders Identification Test (AUDIT): WHO collaborative project on early detection of persons with harmful alcohol consumption-II. Addiction, 88: 791-804.

Shields AL, Caruso JC (2004) A reliability induction and reliability generalization study of the CAGE questionnaire. Educational and Psychological Measurement, 64: 254-70.

Sinclair JMA, Latifi AH, Latifi AW (2008) Co-morbid substance misuse in psychiatric inpatients: prevalence and association with length of inpatient stay. Journal of Psychopharmacology, 22: 92-8.

Sinclair JMA, Bamrah JS, Bowden Jones 0, et al (2012) Alcohol and Other Drugs: Core Medical Competencies. Final Report of the Working Group of the Medical Royal Colleges (Occasional Paper OP85). Royal College of Psychiatrists (https://www.aomrc.org.uk/wp-content/uploads/2016/05/ Alcohol_Drugs_Competencies_0612.pdf).

Sinclair J, Searle E (2016a) Can student health professionals accurately estimate alcohol content in commonly occurring drinks? Therapeutic Advances in Psychopharmacology, 6: 256-62.

Sinclair JM, Chambers SE, Shiles CJ, et al (2016b) Safety and tolerability of pharmacological treatment of alcohol dependence: comprehensive review of evidence. Drug Safety, 39: 627-45.

Sinclair J, Vaccari E, Tiwari A, et al (2019a) Impact of personal alcohol consumption on aspects of medical student alcohol-related competencies. Alcohol and Alcoholism, 54: 325-30.

Sinclair J, McCann M, Sheldon E, et al (2019b) The acceptability of addressing alcohol consumption as a modifiable risk factor for breast cancer: a mixed method study within breast screening services and symptomatic breast clinics. BMJ Open, 9: e027371.

Sullivan JT, Sykora K, Schneiderman J, et al (1989) Assessment of alcohol withdrawal: the revised Clinical Institute Withdrawal Assessment for Alcohol scale (CIWA-Ar). British Journal of Addiction, 84: 1353-7.

Swartz MS, Wagner HR, Swanson JW, et al (2008) The effectiveness of antipsychotic medications in patients who use or avoid illicit substances: results from the CATIE study. Schizophrenia Research, 100: 39-52.

Thomson AD, Marshall EJ (2013) BNF recommendations for the treatment of Wernicke's encephalopathy: lost in translation? Alcohol and Alcoholism, 48: 514-5.

Toftdahl NG, Nordentoft M, Hjorthøj C (2016) Prevalence of substance use disorders in psychiatric patients: a nationwide Danish population-based study. Social Psychiatry and Psychiatric Epidemiology, 51: 129-40.

Treasure J (2004) Motivational interviewing. Advances in Psychiatric Treatment, 10: 331-7.

Weaver T, Madden P, Charles V, et al (2003) Comorbidity of substance misuse and mental illness in community mental health and substance misuse services. British Journal of Psychiatry, 183: 304-13.

World Health Organization (1992) ICD-10: International Statistical Classification of Diseases and Related Health Problems (Tenth Revision). WHO.

World Health Organization (2018) Global Status Report on Alcohol and Health 2018. WHO 
MCOs

Select the single best option for each question stem

1 Which of the following is not true?

a AUD should be considered the expectation, not the exception, in patients presenting to mental health services

b AUD should be screened for in those presenting with anxiety or depression

c increased- and higher-risk levels of alcohol consumption are more prevalent among men than women

d AUD is most common in patients with psychoses

e patients with mental illness and AUD benefit from integrated treatment.

2 Which of the following scales is not recommended in clinical assessments to help identify AUD?

a CAGE

b AUDIT c AUDIT-C

d CIWA-Ar

e GMAWS.

3 Patients at risk of alcohol withdrawal syndrome should be monitored regularly using a standardised alcohol withdrawal scale in order to:

a assess their level of alcohol consumption

b assess whether they are still alcohol dependent

c assess their level of confusion

d assess their potential for behaviour change

e assess their requirements for medication.

4 The simplest and most effective behaviour change technique in relation to drinking is:

a encouraging removal of all alcohol in the patient's household

b attendance at Alcoholics Anonymous

c self-monitoring of alcohol consumption d regular liver function tests

e random breath alcohol tests.

5 The most important intervention for patients with a diagnosis of alcohol dependence or scoring $\geq 20$ on the AUDIT is:

a transfer to an acute medical setting

b assessment for Wernicke-Korsakoff syndrome and the need for thiamine/other vitamin B supplementation

c risk assessment for potential harm to self or others

d intravenous Pabrinex

e confiscation of their car keys. 